\title{
Influence of Social Responsibility Perception on Orthodontic Clinics Clients' Satisfaction
}

\author{
Azade Fatemifar ${ }^{1, *}$ and Masoumeh Rahimzadeh ${ }^{1}$ \\ ${ }^{1}$ MBA, Payame Noor University, Tehran, IR Iran \\ ${ }^{*}$ Corresponding author: Azade Fatemifar, MBA, Payame Noor University, Tehran, IR Iran. Tel: +98-9126158139, E-mail: azade.fatemifar@gmail.com \\ Received 2015 April 18; Accepted 2015 May 20.
}

\begin{abstract}
Background: This paper examine the role that social responsibility can play in advancing orthodontic clinics' management. Social responsibility is a valuable potential area of strategic development that causes consumer's positive perception toward service providers. Objectives: The study also sought to determine the role of social responsibility and trust in strengthening of customer satisfaction. Lack of previous studies caused researcher to analyze the effect of corporate social responsibility on customer trust and satisfaction toward orthodontic clinics in this way.

Materials and Methods: The cause and effect relationship between tree variables were analyzed including social responsibility, trust, customer satisfaction. Having 4 hypotheses. To test the hypotheses the personal questionnaire was used and data from 405 individuals who were the clients of orthodontic clinic in Iran, were collected. Using randomly sampling method and analyzed by statistical instruments. The descriptive statistics was performed using SPSS software and referential statistics was conducted using exploratory and confirmatory factor analysis and structural equation models was done using AMOS software.

Results: Results showed that the positive and significant relationship between social responsibility trust, and also relationship between customer satisfaction and trust were supported. The relationship between corporate social responsibility and customer satisfaction was rejected. Nevertheless, the indirect effect of social responsibility on customer satisfaction was approved.

Conclusions: The results also support that customer trust is the most important attribute in the context of services. In the other word it is trust of clients that lead to client satisfaction.
\end{abstract}

Keywords: Social Responsibility, Social Responsibility, Patients' Trust, Patients' Satisfaction, Orthodontic Clinics

\section{Background}

Health care is one of the many human- oriented services offered. Every part of the healthcare experience must embody and convey the message that the clinic is the center of wellness and health in community (1). Smile is the most visible record of the patient for the dentistry field. The aesthetic restoration of the edentulous patient has a very important psychological effect. Once properly restored, the patient's self-confidence and self-esteem are most of the time improved, which in turn is also the goal of the oral rehabilitation treatment (2). Patient and dentistry clinic relationship have a significant impact on successful treatment in dentistry. Therefore, it is very important to improve this relationship for superior treatment outcomes (3).

For patients, the motivation to undergo orthodontic treatment has a wide range, that is varies from being absolutely uninterested to a strong willingness to undergo treatment (4). Patient commonly think that the doctor-patient interaction should be comfortable and warm with a doctors and clinics who are technically competent and provide adequate care and information about the problem and the procedures they will perform (3). It is understood that the patient trusts after getting the treatment, all patient admitted that the clinics kept their promises and commitment. Thus, the patient satisfaction rely very much on their trust (5). "Trust is the willingness to rely on an exchange partner in whom one has confidence" (6). Sollner et al. (1995) discussed that trust is determined by the three variables of trustworthiness: ability, benevolence and integrity (7).

Orthodontics clinics need to continually build confidence in the patient through the means of satisfying patients and providing better services value than the competitors. Through competition strategy the companies will continue to maintain its superior position, as the nature of competition can lead to creativity and efficiency which in turn benefit the patient (8). Patient' satisfaction is also determined to some extent by their expectations $(9,10)$ based on the standard of comparison they use in evaluating clinic performance (11). They are more likely to be satisfied when the actual performance of clinic confirms or exceeds their prior expectations (12). Social exchange theorists argue that it is natural "to restrict one's transactions to those who have shown themselves to be

Copyright (C) 2015, Iranian Journal of Orthodontics. This is an open-access article distributed under the terms of the Creative Commons Attribution-NonCommercial 4.0 International License (http://creativecommons.org/licenses/by-nc/4.0/) which permits copy and redistribute the material just in noncommercial usages, provided the original work is properly cited. 
Fatemifar A et al.

trustworthy" especially in healthcare field (13). Whereas dependence arises from one party's potential to exercise power or control over another competents or its resources, uncertainty develops from "a lack of perfect knowledge about environmental fluctuations, availability of exchange partners, and available rates of exchange (14).

In order to reduce the associated risk perceptions, people look for signals that indicate a trustworthy business partner (15). Because social responsibility can be regarded as an "informational signal upon which stakeholders base their assessments under conditions of incomplete information" business practice social responsibility reputation is likely to be more important as a signal for trust when market-related uncertainty is high (16). The most famous classification of the dimensions is the one offered by Carroll (1979) that emphasizes the four principle types of responsibilities as dimensions which are economic, legal, ethical and philanthropic. Carroll discussed that these four dimensions are closely related and thus, clinics should strive to achieve all four at all times. In other words, a socially responsible firm "should strive to make a profit, obey the law, be ethical, and be good corporate citizen (17). Thus, the theoretical and empirical evidence has argued that social responsibility activities in consumers' evaluation situation that are perceived more positively lead to higher client satisfaction, trust and loyalty (18).

The academic literature has suggested that if customers are satisfied with their chosen clinic, increasingly they will be inclined to use its services and finally become loyal customers exhibiting strong customer goodwill (19). Social responsibility is a potentially valuable area of strategic development for healthcare providers like dentistry clinics. It has the potential to strengthen the profile of the clinic in the community and to lead to improved financial and clinical performance (20).

\section{Objectives}

So there is a need for research evaluating the relationship between patient's perception of social responsibility of orthodontic clinics and their trust and satisfaction. We hypothesize;

H1: Social responsibility has direct effect on patient's trust

H2: Social responsibility has direct effect on patient's satisfaction

H3: Social responsibility has indirect effect on patient's satisfaction

H4: patient's trust has direct effect on patient's satisfaction.

\section{Materials and Methods}

\subsection{Research Goal}

Based on the literature review, the conceptual model of this study (Figure 1) and the related hypotheses are de- veloped. This study aims not only to understand the possible effect that social responsibility has on Customer-related outcomes such as customer satisfaction and trust, but also to examine the Relationships between trust and satisfaction. To test the hypothesized relationships, a personal questionnaire is conducted.

\subsection{Sampling and Data Collection}

A survey on clients of orthodontic clinic in Iran is conducted to test the hypotheses for empirical research the quantitative survey method and structured data collection was applied. The instrument of the survey was questionnaire composed from structured questions. Paper questionnaires were used to reach respondents. A total of 505 survey instruments were distributed through a random sampling. Of the 485 returned questionnaires 80 were discarded due to high number of missing data, 405 were usable before analysis, variables were examined through various SPSS 18 procedures for accuracy of data entry, missing values, and fit between distributions and the assumptions of structural equation modeling. Eighty cases were identified, through mahalanobis distance analysis, as multivariate outliers with a P value 0.001 . These respondents were deleted, leaving 405 cases for analysis. The majority of respondent were female and results showed 219 females (54.1\%) and 186 males (45.9\%); 20 under the age of $20(4.9 \%), 80$ at the ages of $21-30(19.8 \%), 79$ at the ages of $31-40(19.5 \%), 133$ at the ages of $41-50$ (32.8\%) and 93 over the age of $50(23 \%)$. Most of the respondents, 213 (52.6) have bachelor's degree or higher degree as their latest degree, while 191 (47.4\%) of the respondents also have under bachelor's degrees as their latest degree 87 (21.5\%) of the respondents were under 6 month client of medical center, 43 (10,6\%) between 6 - 12 month, 49 (12.1\%) 1 - 3 years, $52(12.8 \%)$ between 3 - 5 years, 174 (43\%) over 5 years used the services of medical center.

\section{Results}

In order to test the hypothesized relationships described above, scales measuring the constructs of the conceptual model shown in Figure 1 are drawn and adapted from existing literature. All the scales are translated to Persian and then back-translated and the survey instrument is finalized. Before conducting the survey, a pilot test is done with sixty graduate clients with the aim to purify the scales. Social responsibility is measured by the six item developed by Martinez and Rodriguez del Bosque (2013) (19), Perez and del Bosque (2015) (21). In order to measure trust, the five items developed by Morgan and Haunt (1994) (22) and Sollner et al. (7) (1995), and finally for customer satisfaction is measured by Lai (2010) (23), Hsu (2012) (24), Slightly changed to fit and used in the present study. The items for each of these Constructs are measured by seven-point Likert scales $(1=$ strongly disagree, $7=$ strongly agree). During the pretest procedure, respondents were encouraged to comment any 
question that they thought was unclear, ambiguous or that they were unable to answer. Some minor grammatical changes were made to the questionnaire following the pretest process. Nevertheless, none of the items was deleted in response to the expert's comments. The items on the questionnaire were used because they met the criteria for the item analysis.

Before testing the hypotheses via the structural model, we evaluate internal consistency, reliability, and convergent validity of the measures. AMOS 16.0 (maximum likelihood estimation) was employed to complete the analysis. As showed in Table 1, the Cronbach's alpha of each construct is between 0.851 and 0.936 , higher than the 0.7 recommended by Nunnally and Bernstein (1994) (25), demonstrating adequate internal consistency. Composite reliability (CR) of all measures exceed 0.6 threshold suggested by Fornell and Larcker(1981), indicating a favorable level of internal consistency reliability. In addition, the average variance extracted (AVE) across the latent variables exceed the 0.5 benchmark recommended by Fornell and Larcker (1981) (9).

Table 3 shows that variables are significant and the clients have trust, satisfaction and social responsibility perception toward the clinic.

The CFA results support convergent validity for all measures. All estimated regression weights of observed variables for the latent variables are significant at the 0.001 level. A single fit index reflects only a particular aspect of model fit. For this reason, model fit is usually evaluated based on the values of more than one index (Kline 2005). Kline (2005) (26) suggested a minimum set of fit indexes that include the model chi-square (v2), the normed chi-square (v2/DF), the Bentler comparative fit index, the standardized root mean square residual (SRMR), and the root mean square error of approxi- mation (RMSEA) with its 90\% confidence interval. This minimum set of fit indexes should be reported when reporting the results of SEM analyses. Procedure adequate fit Normed:

$\mathrm{X}^{2} / \mathrm{df}=3.12 ; \mathrm{CFI}=0.93 ; \mathrm{RMSEA}=0.07$; and $\mathrm{GFI}=0.93$, AGFI $=0.95, \mathrm{NFI}=0.89, \mathrm{IFI}=0.92, \mathrm{TLI}=0.91$.

Once the measurement model is confirmed, the structural model is then estimated. The model achieves adequate fit. The results show that of 3 paths all of them produce significant coefficient estimates. A summary of results are depicted in Table 3.

There is positive relationship between Social responsibility and trust $(\beta=0.9$, t-value $=15.04$, Sig $<0.05)$ Therefore hypothesis $\mathrm{H} 1$ is supported. The result of relationship between Social responsibility and satisfaction $\beta=$ -0.09 , C.R $=-1.14$, Sig $<0.05$, Therefore hypothesis H2 is rejected. Also there is positive relationship between trust and satisfaction $(\beta=0.56, C . R=5.34$, sig $<0.05)$ so H3 is supported. And also indirect effect of Social responsibility on satisfaction is supported. And also indirect effect of social responsibility on satisfaction $(\beta=0.95)$ therefore hypothesis 4 is supported.

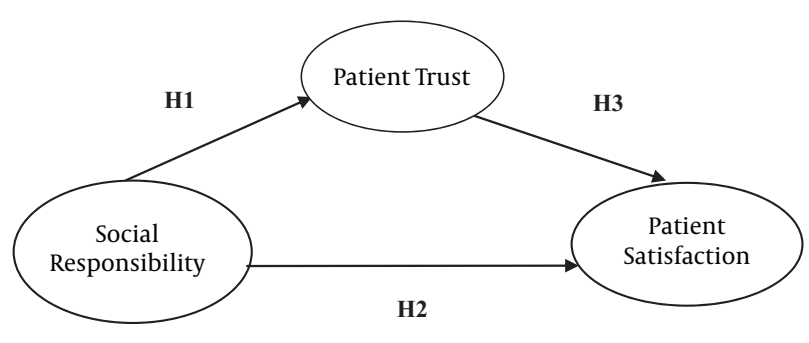

Figure 1. Conceptual Model

Table 1. Result of Validity and Reliability

\begin{tabular}{lccr}
\hline Construct & AVE & CR & Cronbach Alpha \\
\hline Social Responsibility & 0.54 & 0.59 & 0.851 \\
Trust & 0.74 & 0.69 & 0.893 \\
Satisfaction & 0.59 & 0.61 & 0.930 \\
\hline
\end{tabular}

Abbreviation: CR, composite reliability; AVE, average variance extracted.

Table 2. Descriptive Statistic of Variables

\begin{tabular}{|c|c|c|c|c|c|c|c|c|c|c|}
\hline \multirow{2}{*}{ Variables } & \multirow{2}{*}{$\frac{\mathrm{N}}{\text { Statistic }}$} & \multirow{2}{*}{$\begin{array}{c}\text { Minimum } \\
\text { Statistic }\end{array}$} & \multirow{2}{*}{$\begin{array}{c}\text { Maximum } \\
\text { Statistic }\end{array}$} & \multirow{2}{*}{$\begin{array}{c}\text { Mean } \\
\text { Statistic }\end{array}$} & \multirow{2}{*}{$\frac{\text { Std. Deviation }}{\text { Statistic }}$} & \multirow{2}{*}{$\begin{array}{l}\text { Variance } \\
\text { Statistic }\end{array}$} & \multicolumn{2}{|c|}{ Skewness } & \multicolumn{2}{|c|}{ Kurtosis } \\
\hline & & & & & & & Statistic & Std. Error & Statistic & Std. Error \\
\hline $\begin{array}{l}\text { Social } \\
\text { responsibility }\end{array}$ & 405 & 1.00 & 7.00 & 5.784 & 0.827 & 0.686 & -0.693 & 0.092 & 1.636 & 0.185 \\
\hline Trust & 405 & 1.00 & 7.00 & 5.898 & 0.916 & 0.840 & -1.433 & 0.092 & 1.751 & 0.185 \\
\hline Satisfaction & 405 & 1.00 & 7.00 & 5.862 & 1.109 & 1.230 & 1.725 & 0.092 & 1.988 & 0.185 \\
\hline Valid $\mathrm{N}$ (list wise) & 405 & & & & & & & & & \\
\hline
\end{tabular}


Fatemifar A et al.

\begin{tabular}{lcccccc}
\hline Table 3. Mean Differences of Variables & & & & & \\
\hline \multirow{2}{*}{ Variables } & T Value & df & Sig. (2-Tailed) & Mean Difference & 95\%Confidence Interval of the Difference \\
\cline { 5 - 7 } & & & & & Lower & Upper \\
\hline Trust & 96.946 & 405 & 0.000 & 26.20616 & 25.6733 & 26.7390 \\
Satisfaction & 96.777 & 405 & 0.000 & 26.07820 & 25.5470 & 26.6094 \\
Social Responsibility & 103.94 & 405 & 0.000 & 31.39573 & 30.7977 & 31.9938 \\
\hline
\end{tabular}

\begin{tabular}{lccc}
\hline \multicolumn{2}{l}{ Table 4. Summary of the Hypothesized Structural Paths for Models ${ }^{\mathrm{a}, \mathrm{b}}$} & & \\
\hline Hypotheses & Structural Paths & Std. Coefficient $(\mathbf{C . R})$ & Result \\
\hline H1 & Social responsibility trust & $0.9(15.04)^{\mathrm{b}}$ & Supported \\
H2 & Social responsibility satisfaction & $-0.09(-1.14)$ & Rejected \\
H3 & Trust satisfaction & $0.56(5.34)^{\mathrm{b}}$ & Supported \\
H4 & Social responsibility trust satisfaction & $0.95^{\mathrm{b}}$ & Supported \\
\hline
\end{tabular}

${ }^{\mathrm{a}} \mathrm{X}^{2} / \mathrm{df}=3.12 ; \mathrm{CFI}=0.93 ; \mathrm{RMSEA}=0.07 ; \mathrm{GFI}=0.93 ; \mathrm{AGFI}=0.95 ; \mathrm{NFI}=0.89 ; \mathrm{IFI}=0.92 ; \mathrm{TLI}=0.91$.

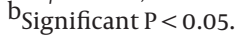

\section{Discussion}

Delivering patient satisfaction is at the heart of modern healthcare marketing strategy, which is post purchase judgement of patients. The successful practice of orthodontics is significantly depend on interaction between the orthodontic clinic and the patient. This relationship in orthodontics can positively influence treatment outcomes by encouraging the patient to cooperate in following prescribed instructions. In the field of medical services, Kumar (1) (2008) adopted the concept of customer satisfaction and defined that patient satisfaction is the judgement of perceived value sustained response toward service related stimulus before, during or after the consumption of medical services by the patient. Several reports in the literature have argued that when patient's expectations are not met they feel disappointed, less satisfied, fail to keep appointment, and do not comply prescribed instruction. This study examines the effect that social responsibility has on customer related outcomes such as patient satisfaction and trust and also investigate the effect of patient trust on patient satisfaction. Theoretically, this study makes a number of contributions to literature. It test and confirm social responsibility plays important role to achieving trust. Thus, this study expands the traditional view concerning social responsibility's effect on customers and suggest that social responsibility create more trust and hence, more satisfy customer and suggests that social responsibility associations do not only affect product evaluation, but also increase customer trust. Customers are more likely to believe that responsible orthodontic clinics operate honestly in their activities and reflect interests of both parties in the relationship when making decisions, which contribute to the trustworthiness and honesty of these clinics. Moreover, patients are more willing to relate with clinics carrying out socially responsible initiatives Thus, this study adds additional empirical evidence to the recent observation of the positive effect of social responsibility on patient trust $(16,27,28)$ and positive influence of trust on satisfaction (29-31). And finally, it is important to note that the direct effect of social responsibility on patient satisfaction is not significant. These findings surprisingly contradict results from $(32,33)$, who established a positive influence of social responsibility on consumer satisfaction. But the indirect effect of social responsibility via client trust supported. However, these authors argue that the role of social responsibility on satisfying patients is not likely one that lasts forever and is highly dependent on other factors. The results also support that patient trust is the most important attribute in the context of services. In the other word it is trust of clients that lead to client satisfaction. From managerial perspective, one of the important findings of this study was the demonstration of the close link between social responsibility and trust. The results suggest that the more clients perceive a clinic to be socially responsible, the more they trust the clinic. The results provide an initial perspective evidence of the importance of social responsibility and trust into the rapidly growing client satisfaction stream in orthodontic clinics. In addition clinic manager should orient doctors, nurses and other clinic staff to approach new and experienced clients differently. Clients are sensitive to their own expectation as well. This means that clinic staff and doctors should focus on managing that expectation more closely. For example providing realistic waiting time estimates and amount of time the doctors have to spend interacting with the patients. An improvement in patients' perception of these factors such as being social responsible, obeying hygiene rules and standards, feel security with services of orthodontic clinics are required rather than putting emphasis additional resources. This study has some limitations that future scholars have to address. This study tests 
the hypothesis with clinic consumers based on a convenient sample from an orthodontic clinic in Iran. Future research should test this model with larger random samples or samples in other contexts. The authors have not addressed possible differences in the social responsibility expectations among patients. Thus, it is not possible to determine whether different types of social responsibility dimensions could have impacts on patient trust and satisfaction that are more positive than the others are.

\section{References}

1. Kumar N. Impact of Healthcare Marketing \& Branding on hospital services. JRFHHA. 2014;2(1):19-24.

2. Lakshmi S, Abraham A, Selvakumaran G, Sekar V, Annapoorni $\mathrm{H}$. Influence of aesthetic dental and facial measurements on patient satisfaction between genders in Indian patients. Tanta Dental J. 2015;12(3):197-202.

3. Sinha PK, Nanda RS, McNeil DW. Perceived orthodontist behaviors that predict patient satisfaction, orthodontist-patient relationship, and patient adherence in orthodontic treatment. Am J Orthod Dentofacial Orthop. 1996;110(4):370-7. [PubMed: 8876486]

4. Pacheco-Pereira C, Pereira JR, Dick BD, Perez A, Flores-Mir C. Factors associated with patient and parent satisfaction after orthodontic treatment: a systematic review. Am J Orthod Dentofacial Orthop. 2015;148(4):652-9. [PubMed:26432321]

5. Solayappan A, Jayakrishnan J. Key determinant of brand -customer relationship in hospital industry. Am J Orthod Dentofacial Orthop. 2010;12(4):119-28.

6. Moorman C, Deshpande R, Zaltman G. Factors affecting trust in market research relationships. J Mark. 1993:81-101.

7. Söllner M, Leimeister JM. What we really know about antecedents of trust: A critical review of the empirical information systems literature on trust. JPsych. Trust. 2013;7:127-40.

8. Purwanto Y. The effect of service delivery performance and corporate social responsibility on institutional image and competitive advantage and its implication on customer trust. Issues Soc. Environ. Acct. 2012;4(2):168-85.

9. Fornell C, Larcker DF. Evaluating Structural Equation Models with Unobservable Variables and Measurement Error. J. Mark. Res. 1981;18(1):39-50.

10. Oliver RL. Whence Consumer Loyalty? JMark. 1999;63:33-44.

11. Parasuraman A, Zeithaml V, Berry L. SERVQUAL: a multiple-item scale for measuring consumer perceptions of service quality. $J$ Retailing. 2002;64(1):140.

12. Siu N, Yee-Man Z, Tracy J, Kwan H. Effect of corporate social responsibility, customer attribution and prior expectation on post-recovery satisfaction. Int J Hosp Manag. 2014;43:87-97.

13. Peter K. The Emergence of Exchange Structures: An Experimental Study of Uncertainty, Commitment, and Trust. Amer. J. of Sociol. 1994;100(2):313-45.

14. Oliver RL. Whence Consumer Loyalty? J. Mark. 1999;63:33-44. doi: $10.2307 / 1252099$.
15. Connelly Brian LS, Trevis Certo R, Duane I, Christopher RR. Signaling Theory: A Review and an Assessment.J Manag. 2011;37(1):39-67.

16. Christian H, Marcel S, Torsten B. Corporate Social Responsibility in Business-to-Business Markets: How Organizational Customers Account for Supplier Corporate Social Responsibility Engagement. J.Mark. 2013;77(6):54-72.

17. Carroll AB. Corporate social performance measurement: A commentary on methods for evaluating an elusive construct. Res. Corporate Soc. Perform. policy. 1991;12(42):385-401.

18. Chung KH, Yu JE, Choi MG, Shin JI. The Effects of CSR on Customer Satisfaction and Loyalty in China: The Moderating Role of Corporate Image. J. Econ. Bus. Managem. 2006.

19. Martinez P, Rodriguez del Bosque I. CSR and customer loyalty: The roles of trust, customer identification with the company and satisfaction. Int J Hosp Manag. 2013;35:89-99.

20. Takahashi T, Ellen M, Brown A. Corporate social responsibility and hospitals: US theory, Japanese experiences, and lessons for other countries. Healthc Manage Forum. 2013;26(4):176-83. [PubMed: 24696941]

21. Perez A, del Bosque IR. An integrative framework to understand How CSR affect customer loyalty through Identification, Emotions and Satisfaction. J Bus Ethics. 2015;129(3):571-584.doi: 10.1007/s10551-014-2177-9.

22. Morgan R, Hunt SD. The commitment-trust theory of relationship marketing. Journal of Marketing.1994;58(3):20-38.

23. Lai C, Chiu C, Yang C, Pai D. The effect of corporate social responsibility on brand performance: the mediating effect of industrial brand equity and corporate reputation. J Bus Ethics. 2010;95(3):457-469.doi:10.1007/S10551-010-0433-1.

24. Hsu K. The advertising effect of corporate social responsibility on corporate reputation and brand equity: evidence from the life insurance industry. J Bus Ethics. 2012;109(2):189-201 doi: 10.1007/S10551-011-1118-0.

25. Nunnally JC, Bernstein IH. Psychometric theory (3rd ed.). New York, NY: McGraw-Hill, Inc. 1994.

26. Kline RB. Principle and practice of structural equation modeling. New York: Guilford. 2005.

27. Pivato S, Misani N, Tencati A. The impact of corporate social responsibility on consumer trust: the case of organic food. Bus Ethics. 2008;17(1):3-12.

28. Hong SY, Rim H. The influence of customer use of corporate websites: Corporate social responsibility, trust, and word-of-mouth communication. Public Relat Rev. 2010;36(4):389-91.

29. Ajzen I, Fishbein M. Understanding attitudes and predicting social behaviour. Prentice-Hall Press. 1980.

30. Christou E. Relationship marketing practices for retention of corporate customers in hospitality contract catering. Tourism and Hospitality Management. 2010;16(1):1-10.

31. Yuksel E, Graham MR, Philip DL. An extended model of the antecedents and consequences of consumer satisfaction for hospitality services. Eur J Mark. 2008;42(1/2):35-68.

32. Luo X, Bhattacharya CB. Corporate social responsibility, customer satisfaction, and market value. J Mark. 2006;70(4):1-18.

33. He H, Li Y. CSR and service brand: The mediating effect of brand identification and moderating effect of service quality. J Bus Ethics. 2011;100(4):673-88. 